\title{
Communication Skills Training for Residents: Which Variables Predict Learning of Skills?
}

\author{
Isabelle Bragard ${ }^{1}$, Isabelle Merckaert ${ }^{2}$, Yves Libert ${ }^{3}$, Nicole Delvaux ${ }^{4}$, Anne-Marie Etienne ${ }^{1}$, \\ Serge Marchal $^{3}$, Christine Reynaert ${ }^{5}$, Darius Razavi ${ }^{2}$ \\ ${ }^{1}$ Health Psychology Unit, University of Liège, Liège, Belgium \\ ${ }^{2}$ Psychosomatics and Psycho-Oncology Research Unit, Free University of Brussels, Brussels, Belgium \\ ${ }^{3}$ Jules Bordet Institute, Brussels, Belgium \\ ${ }^{4}$ Psychology Department, Erasme Hospital, Brussels, Belgium \\ ${ }^{5}$ Université Catholique de Louvain, Louvain-la-Neuve, Belgium \\ Email: isabelle.bragard@ulg.ac.be
}

Received June 7, 2012; revised July 28, 2012; accepted August 13, 2012

\begin{abstract}
Objective: This study aimed to determine variables associated (predictors and correlates) with the learning of assessment and supportive skills in the context of a communication skills training for medical residents. Methods: Learning was measured by comparing residents' communication skills in a simulated consultation before and after a communication skills training. Communication skills were transcribed and tagged with a computer-assisted program. Potential variables associated with learning (residents' characteristics, contextual characteristics and pre-training communication skills) were measured before the training and entered in regression analysis. Results: Fifty-six residents followed the training between 2002 and 2006. Poor pre-training assessment and supportive skills predicted the respective learning of these skills. Better assessment skills' learning was predicted by copings (i.e. lower level of emotional coping), lower levels of self-efficacy and depersonalization. Better supportive skills' learning was predicted by a lower work experience and associated with a higher training attendance rate. Conclusions: Predictors and correlates of assessment and supportive skills learning were different. Trainers needed to detect certain residents' characteristics (i.e. depersonalization) in order to optimize assessment skills learning. Trainers needed to be aware that supportive skills are difficult to learn and to teach and may need more training hours.
\end{abstract}

Keywords: Communication Skills Training; Medical Residents; Assessment and Supportive Skills; Predictors and Correlates of Learning

\section{Introduction}

Communication is now recognized as a core clinical skill in medicine in general and in cancer care in particular. Physicians should ideally be able to use effective communication skills that allow them to assess [1], inform [2] and support [3] patients adequately. These skills are key skills in a patient-centered communication leading to patients' disclosure of concerns [4-8] and to an increased patient's satisfaction and adherence to medical treatment [9]. However, physicians often lack ability to assess levels of patient depression and anxiety [10] and pay little attention to patients concerns [11]. Physicians lack also ability to support patients adequately. Moreover, using appropriate assessment skills allows to support and to give patients adequate information and using appropriate supportive skills allows to assess further their concerns [12]. Assessment and supportive skills are both useful and should be learned.
Teaching communication skills has increased over the last 40 years in the entire continuum of medical education [13]. Some studies have shown the efficacy of learner-centred, skills-focused and practice-oriented communication skills training programs on communication skills learning [14-16]. However, other studies show that these training programs are not sufficient to establish improved communication behavior of physicians [17-19]. In theory, knowledge about predictors and correlates of learning may be helpful for designing more effective communication skills training programs.

To our knowledge, only one study has explored variables associated with learning of communication skills among physicians [20]. This study showed that an internal locus of control (referring to a generalized belief regarding the extent to which life outcomes are controlled by an individual's actions) facilitated communication skills acquisition among oncologists through physicians' belief that communication with patients may be con- 
trolled by physicians themselves [20].

So, there is a need to investigate variables associated with the learning of assessment and supportive skills among physicians in the context of a communication skills training. It is important to consider variables which are potential predictors and correlates of learning: age, professional experience, anxiety, self-efficacy, locus of control, motivation, value and belief attached to learning outcomes, professional climate, support from supervisor and peers and of course pre-training skills level [21]. These variables may be categorized into residents' characteristics (sociodemographic, professional, psychological characteristics), contextual characteristics (professional environment) and pre-training communication skills (see Figure 1). It may be hypothesized that predictors and correlates of the learning of assessment and supportive skills are quite different.

\section{Methods}

\subsection{Subjects}

To be included in this study, medical residents had to speak French and to be willing to participate in the training program and its assessment procedure. Residents had also to have worked, be working with, or be in a project working with, cancer patients (part or full time). Residents participating in another psychological training program during the assessment and training periods were excluded from the study.

\subsection{Study Design and Assessment Procedure}

Figure 1 shows the potential predictors and correlates of residents' learning of assessment and supportive skills in the context of a communication skills training. Residents' learning of these skills could be influenced by residents' characteristics (sociodemographic, professional and psychological), contextual characteristics (professional environment), pre-training communication skills and training attendance. Residents' learning of communication skills has been measured in a breaking bad news consultation with a simulated patient performed before and after a communication skills training in the context of a randomized controlled study. Residents and contextual characteristics have been measured with questionnaires. For this study, data came only from the residents included in the training group. The study was approved by each hospital Institutional Review Board.

\subsection{Training Program}

The training program included a 30-hour communication skills training in small groups (up to 7 participants). The teaching method was learner-centred, skill-focused, and practice-oriented. The communication skills training offered some theoretical information presenting adequate communication skills. In the other sessions, residents were invited to practice the principles discussed in the theoretical sessions through role-plays with immediate feedback offered by experienced facilitators. This program has been described in details elsewhere [22].

\subsection{Assessment of Communication Skills Learning}

Residents' learning of assessment and supportive skills was assessed in an audiotaped breaking bad news simulated consultation. Simulated consultations have been described as a valid method to study communication style [23]. It implied a task of breaking a breast cancer diagnosis to an actress playing a patient. The actress was trained to carefully maintain the same behaviors and high emotional level over the entire study. She was in structed to express concerns about the medical and marital consequences of the disease. Before the simulated consultation, residents had enough time to complete some questionnaires and to learn the case description. They were then introduced to the actress and told that, after 20 minutes, the consultation would be put to an end. A clock was available for time management, and the recording room was made to look as realistic as possible. After the simulated consultation, physicians had to complete questionnaires. The audiotapes of the simulated consultations were transcripted. Transcripts were analyzed by the LaComm software. LaComm is a French communication content analysis software. This software uses a word count strategy based on categories of words like Protan [24] and a word combination strategy like the General Inquirer [25]. The aim of this soft ware is to analyze, utterance by utterance, verbal communication used (in medicine in general and in oncology in particular) by identifying utterance types and contents. For this study, only the types of utterances were used. Types of residents' utterances were analyzed with the dictionaries included in the LaComm. Dictionaries are composed of words, word stems or expressions and were built on the basis of empirical knowledge derived from actual and simulated patient consultations performed by physicians [26]. The categories of dictionaries were adapted from the categories of the Cancer Research Campaign Workshop Evaluation Manual [27] and redefined according to the three-function approach of the medical interview [28] by a panel of experts. Utterances were categorized in three main types: assessment, sup port, and the information. This study focused on assessment and support types of utterances (See Table 1). The content analysis software has been shown to be effective in measuring improved communication skills [29,30]. It allows analyses 


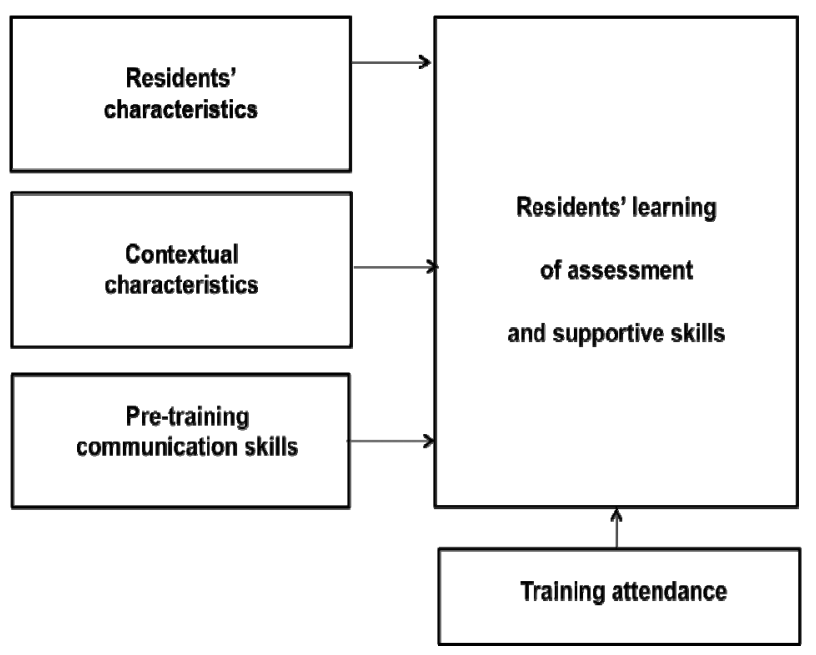

Figure 1. Predictors and correlate of residents' learning of assessment and supportive skills.

Table 1. Description of the assessment and support types of utterances.

\begin{tabular}{|c|c|c|}
\hline Types of utterances & Definitions & Examples \\
\hline \multicolumn{3}{|l|}{ Assessment } \\
\hline Open questions & $\begin{array}{l}\text { Assessment of a wide } \\
\text { range of issues, } \\
\text { concerns, or feelings. }\end{array}$ & $\begin{array}{l}\text { How are you doing? } \\
\text { Tell me. }\end{array}$ \\
\hline $\begin{array}{l}\text { Open directive } \\
\text { questions }\end{array}$ & $\begin{array}{l}\text { More focused } \\
\text { assessment of issues, } \\
\text { concerns, or feelings. }\end{array}$ & $\begin{array}{l}\text { Tell me what occured } \\
\text { since the last treatment; } \\
\text { What do you feel about it? }\end{array}$ \\
\hline \multicolumn{3}{|l|}{ Support } \\
\hline Acknowledgement & $\begin{array}{l}\text { Support by listening to } \\
\text { the patient. }\end{array}$ & $\begin{array}{l}\text { Mh., Mh.; Right.; } \\
\text { That should not be easy. }\end{array}$ \\
\hline Empathy & $\begin{array}{l}\text { Support by showing an } \\
\text { understanding of the } \\
\text { patient's emotional or } \\
\text { physical state. }\end{array}$ & $\begin{array}{l}\text { I understand that you are } \\
\text { distressed. I realize that } \\
\text { you have severe pain. }\end{array}$ \\
\hline
\end{tabular}

of verbal communications which reflect important aspects of medical interactions. It is important to underline that this software is only useful to assess training effects and is not designed for teaching.

\subsection{Assessment of Residents' Characteristics}

Residents' socio-demographic characteristics were assessed with a socio-demographic questionnaire (age and gender). Residents' professional characteristics were assessed with a socio-professional questionnaire (medical speciality, oncology work experience in years) and a Professional Career questionnaire specifically developed for this study. Residents' psychological characteristics were assessed with the following questionnaires: General Health Questionnaire (GHQ-28) [31], Rotter InternalExternal Scale [32], Psychological State of Stress Measure (PSSM) [33], State-Trait Anxiety Inventory Trait form $\mathrm{Yb}$ (STAI-Yb) [34], Maslach Burnout Inventory (MBI) [35], Ways of Coping Checklist (WCC) [36] and three questionnaires specifically developed for this study (Motivation to learn, Valence, Self-Efficacy).

Professional Career. This is a 8-item self-reported instrument adapted from Colquitt et al. [21] scored on a 10 $\mathrm{cm}$ visual analogue scale (VAS) ranged from 0 (not at all) to 10 (completely). Items measured residents' implication in work, organisational engagement, implication in career, exploration of the career, and planning of the career.

GHQ-28 [31]. This validated French-translated 28item questionnaire assesses short-term changes in mental health.

Rotter Internal-External Scale [32]. This validated French-translated 30-item questionnaire measures residents' locus of control (LOC), referring to their perceived ability to influence events in their own life.

PSSM [33]. This validated French instrument evaluates the subjective experience of feeling stressed over the last 48 hours.

STAI-Yb [34]. This 20-item questionnaire measures relatively stable individual differences in anxiety processes. The French-language version has been validated.

MBI [35]. This validated French-translated 22-item questionnaire assesses residents' level of burnout (emotional exhaustion, depersonalization and personal accomplishment).

WCC [36]. This validated French-translated 27-item scale assessed: problem-focused coping aiming at solving the problem that faces the person, emotion-focused coping involving cognitive processes directed at lessening emotional distress and social support-focused coping aiming at finding others' support.

Motivation to learn. This is a 1-item self-reported instrument adapted from Colquitt et al. [21] ("At present and in the context of this training, I'm motivated to learn to better communicate in an consultation with a cancer patient") scored on a $10 \mathrm{~cm}$ visual analogue scale (VAS) ranged from 0 (moderately motivated) to 10 (extremely motivated).

Valence. This 3-item questionnaire adapted from Colquitt et al. [21] assessed the value according by residents to effective communication skills during consultations on a $10 \mathrm{~cm}$ visual analogue scale (VAS). The internal reliability was high (Cronbach's alpha $=0.80$ ).

Self-efficacy. This 13-item scale adapted from Parle et $a l$. [37] assesses residents' perception of their own ability to communicate and to manage stress in consultation with a cancer patient. A factorial analysis has lead to 4 factors: elicitation of concerns (Cronbach's alpha $=0.79$ ), detection of distress $(\mathrm{r}=0.62)$, complex communication skills such as breaking bad news (Cronbach's alpha $=$ 0.61 ), and stress management (Cronbach's alpha $=0.76$ ). 


\subsection{Assessment of Contextual Characteristics}

Contextual characteristics were assessed with the Job Stress Survey (JSS) [38]. This validated French-translated 30-item questionnaire assesses the perceived intensity and frequency of occurrence of job-related stressor events that are likely to affect the psychological wellbeing of employees who have been exposed to them during the preceding 6 months. Summing the ratings of each item provides an overall Job Stress Index.

\subsection{Statistical Analysis}

Residents' learning of assessment and supportive skills were computed through the difference between residents' skills at baseline and after training. Stepwise Multiple Regression Analysis was computed to examine predictors and correlate of residents' learning of assessment and supportive skills. Two models have been tested respectively for assessment skills and supportive skills. A preliminary analysis was used to identify predictors and correlates among residents' characteristics, contextual characteristics, pre-training communication skills and training attendance (Pearson's correlations, t-tests for independent sample or one-way ANOVA as appropriate). Variables were entered in the regression analyses if they satisfied the inclusion criterions (i.e., $\mathrm{p}<0.05$ ). The analyses were performed with SPSS for windows, version 13.0 [39].

\section{Results}

\subsection{Subjects}

One-hundred and thirteen residents registered for the study between 2002 and 2006 and 61 followed the training program in the training group. Residents were from the three French-speaking universities in the country and worked in several hospitals and clinics at the time of the study. Barriers to participation included mainly personal and institutional reasons, time limitations, training duration and time-consuming assessment procedures. Five participants were excluded because they did not complete assessment procedure 8 months later. The final sample for this study included fifty-six residents. Comparison of included and excluded residents showed no statistically significant differences for gender, age or number of years of practice.

As shown in Table 2, residents were a mean of 28 years old ( $\mathrm{SD}=3$ years), $70 \%$ were female. Nine percent were in oncology (oncology, haematology and radio therapy), $30 \%$ in gynaecology and $61 \%$ in other speciali ties (e.g. surgery, gastroenterology). They had a mean of 2 years of oncology work experience $(\mathrm{SD}=2.5$ years). They took part on average to 15 hours of training $(\mathrm{SD}=$ 8.3).

\subsection{Residents Learning of Assessment and Supportive skills}

On average, there was a difference of $1.3(\mathrm{SD}=3.1$, with a minimum of -4 , a maximum of 12 ) between residents' assessment skills before and after training. There was a difference of 3 ( $\mathrm{SD}=16.3$, with a minimum of -38 , a maximum of 40) between residents' supportive skills before and after training.

\subsection{Variables Related to Residents' Learning of Assessment and Supportive Skills: Univariate Analysis}

Table 2 shows variables related to learning of assessment and supportive skills. Concerning the learning of assessment skills, five psychological characteristics were significantly associated: depersonalization $(\mathrm{p}=0.040)$, motivation to learn ( $\mathrm{p}=0.023)$, self-efficacy beliefs as regard detection of patient distress $(p<0.001)$, emotional-focused coping $(\mathrm{p}=0.028)$, and social support-focused coping $(\mathrm{p}=0.017)$. Moreover, pre-training assessment skills $(\mathrm{p}=0.031)$ and training attendance $(\mathrm{p}=$ 0.027 ) were significantly associated.

Concerning the learning of supportive skills, one sociodemographic characteristic (age $(\mathrm{p}=0.047)$ ), one professional characteristic (oncology work experience $(\mathrm{p}=$ $0.007)$ ), and one psychological characteristic (self-efficacy beliefs as regard detection of patient distress ( $p=$ $0.045)$ ) were significantly associated. Moreover, pretraining supportive skills $(\mathrm{p}<0.001)$ and training attendance $(\mathrm{p}=0.005)$ were also significantly associated.

\subsection{Variables Related to Residents' Learning of Assessment and Supportive Skills: Multiple Regression Analysis}

Table 3 shows variables predicting or being associated with residents' learning of assessment and supportive skills. Given that all physicians were young, we have only entered "work experience" and not "age" in the re gression model. Characteristics entered into the regression model explained $49 \%$ of the variance in residents' learning of assessment skills and $37 \%$ of the variance in residents' learning of supportive skills. Results showed negative associations between residents' learning of as sessment skills and depersonalization $(p=0.037)$, selfefficacy beliefs as regard detection of patient distress ( $p$ $<0.001)$, emotional-focused coping $(\mathrm{p}=0.001)$, and pre-training assessment skills $(\mathrm{p}=0.012)$, and a positive association with social support-focused coping ( $\mathrm{p}=$ 0.001). Results showed negative associations between residents' learning of supportive skills and oncology work experience $(\mathrm{p}=0.010)$ and pre-training supportive skills $(\mathrm{p}=0.001)$ and a positive association with training attendance $(\mathrm{p}=0.007)$. 
Table 2. Variables related to residents' learning of assessment and supportive skills ${ }^{1}(n=56)$.

\begin{tabular}{ccc}
\hline Variables & $\begin{array}{c}\text { Learning of } \\
\text { assessment } \\
\text { skills }\end{array}$ & $\begin{array}{c}\text { Learning of } \\
\text { supportive } \\
\text { skills }^{2}\end{array}$ \\
\hline $\mathrm{r}$ & $\mathrm{r}$
\end{tabular}

Residents' characteristics

1. Sociodemographic characteristics

Age

$-0.08 \quad-0.27^{*}$

2. Professional characteristics

Oncology work experience in years

$-0.13$

$-0.36^{* *}$

3. Psychological characteristics

3.1. Burnout level

3.1.1. Emotional Exhaustion

$\begin{array}{ll}-0.09 & 0.12 \\ -0.06 & 0.10 \\ -0.28^{*} & 0.14 \\ 0.30^{*} & -0.04\end{array}$

3.1.2. Personal Accomplishment

3.1.3. Depersonalization

3.2. Motivation to learn

communication skills

3.3. Self-efficacy

3.3.1. Concern's patient evaluation

3.3.2. Complex strategy

communication use

3.3.3. Distress' patient detection

3.3.4. Stress management

3.4. Coping in interview

3.4.1. Problem-focused coping

3.4.2. Emotional-focused coping

3.4.3. Social support-focused coping

$-0.17$

$-0.16$

$-0.02$

$-0.46^{* * *}$

$-0.27^{*}$

$-0.22$

$-0.22$

Pre-training communication skills

1. Pre-training assessment skills

2. Pre-training supportive skills

Training attendance (in hours)

$\begin{array}{cc}0.13 & -0.04 \\ -0.29 * & -0.08 \\ 0.32 * & 0.10\end{array}$

$\begin{array}{cc}-0.29^{*} & -0.26 \\ 0.08 & -0.48^{* * *} \\ 0.30^{*} & 0.37^{* *}\end{array}$

${ }^{*} \mathrm{p} \leq 0.05 ;{ }^{* *} \mathrm{p} \leq 0.01 ;{ }^{* * *} \mathrm{p} \leq 0.001 ;{ }^{1}$ Computed through Pearson correlation; ${ }^{2}$ Computed through the difference between residents' scores at Baseline and 8 months later. Abbreviations: $\mathrm{r}$ - pearson correlation.

\section{Discussion}

This study aims to determine variables (among residents' characteristics, contextual characteristics, pre-training skills and training attendance), which predict or are associated with the learning of assessment and supportive skills following a communication skills training. First, our results show that low levels of both pre-training assessment and supportive skills predict a better learning of these respective skills.

Second, our results show that predictors and correlates of assessment and supportive skills learning are different. Residents' learning of assessment skills is neither related to their socio-demographic, nor to their professional characteristics, nor to the contextual characteristics. Residents' learning of assessment skills is meanwhile predicted by some psychological characteristics. First, certain types of residents' copings (low level of emo-
Table 3. Variables related to residents' learning ${ }^{1}$ of assessment and supportive skills (Stepwise Multiple Regression Analysis) ( $\mathbf{n}=56)$.

\begin{tabular}{|c|c|c|c|c|}
\hline \multirow[t]{2}{*}{ Variables } & \multicolumn{2}{|c|}{$\begin{array}{c}\text { Learning of } \\
\text { assessment skills }\end{array}$} & \multicolumn{2}{|c|}{$\begin{array}{c}\text { Learning of } \\
\text { supportive skills }\end{array}$} \\
\hline & $\beta$ & $\mathrm{p}$ & $\beta$ & $\mathrm{p}$ \\
\hline \multicolumn{5}{|l|}{ Residents' characteristics } \\
\hline \multicolumn{5}{|l|}{ 1. Professional characteristics } \\
\hline $\begin{array}{l}\text { Oncology work experience (in } \\
\text { years) }\end{array}$ & - & - & $\begin{array}{c}-0.29 \\
2\end{array}$ & 0.010 \\
\hline \multicolumn{5}{|l|}{ 2. Psychological characteristics } \\
\hline General health (GHQ) & - & - & - & - \\
\hline \multicolumn{5}{|l|}{ Burnout (MBI) } \\
\hline Depersonalization & -0.212 & 0.037 & - & - \\
\hline \multicolumn{5}{|l|}{ Self-efficacy in interview } \\
\hline Distress' patient detection & -0.430 & 0.000 & - & - \\
\hline \multicolumn{5}{|l|}{ Coping in interview (WCC) } \\
\hline Emotional-focused coping & -0.344 & .001 & - & - \\
\hline Social support-focused coping & 0.344 & 0.001 & - & - \\
\hline \multicolumn{5}{|l|}{$\begin{array}{l}\text { Pre-training communication } \\
\text { skills }\end{array}$} \\
\hline $\begin{array}{l}\text { 1. Pre-training assessment } \\
\text { skills }\end{array}$ & -0.258 & 0.012 & - & - \\
\hline 2. Pre-training supportive skills & - & - & $\begin{array}{c}-0.38 \\
1\end{array}$ & 0.001 \\
\hline Training attendance (in hours) & - & - & 0.308 & 0.007 \\
\hline Constant & & 0.009 & & 0.105 \\
\hline Multiple R & & 0.734 & & 0.641 \\
\hline Adjusted $\mathrm{R}^{2}$ & & 0.493 & & 0.366 \\
\hline $\mathrm{F}$ & & 11.69 & & 11.60 \\
\hline $\mathrm{p}$ & & $<0.001$ & & $<0.001$ \\
\hline
\end{tabular}

${ }^{1}$ Computed through a difference between residents' scores at baseline and 8 months later; ${ }^{2}$ Variables entered in the analysis and excluded: training attendance and motivation to learn communication skills in interview; ${ }^{3}$ Variables entered in the analysis and excluded: oncology work experience, self-efficacy in interview as regard distress' patient detection. Abbreviations: GHQ - General Health Questionnaire; MBI-Maslach Burnout Inventory; WCC - Ways of Coping Checklist.

tional-focused coping and high level of social supportfocused coping) predict better assessment skills learning. On the one hand, emotional-focused coping (i.e. "I have wished that the situation disappears") predicts a poorer learning of assessment skills. Residents who are using this coping may be less motivated to learn assessment skills, which do not match with their usual coping tending to avoid to explore patients concerns. On the other hand, social support-focused coping (i.e. "I have sought professional's help and I did what this professional has recommended") referring to a tendency to find solutions to problems by seeking other's help predicts a better learning of assessment skills. Residents may be sensitive to patients support needs because they are using themselves social support-focused coping to deal with stressors. Residents may be therefore more motivated to learn assessment skills.

Residents' belief about their own competence-low level of self-efficacy belief - as regard detection of pa- 
tients' distress predicts also better assessment skills learning. Residents who belief to be already competent in the detection of patients' distress may be less motivated to learn assessment skills that aim to detect patients concerns. Residents' negative attitude towards patientshigh level of depersonalization - predicts lower assessment skills learning. This may be explained by the fact that residents who are not prone to personalize their relationship with patients (i.e. "I don't really care what happens to my patients") may be less motivated to learn assessment skills.

Factors associated with learning of supportive skills are different. Residents' learning of supportive skills is not related to the psychological characteristics collected in this study. Our results show that supportive skill learning is predicted by a lower professional experience and is associated with a higher training attendance rate. The fact that a low professional experience predicts more supportive skills learning may be explained by the fact that residents with limited work experience have less established ways to support their patients and may be motivated to learn skills. Moreover, the result concerning the training attendance rate may be explained by the fact that supportive skills are less easy to learn than assessment skills and by the fact that supportive skills are usually learned after assessment skills.

Our study did not confirm the association between physicians' locus of control and communication skills learning reported by Libert et al. [20]. Two reasons may explain this difference. First, Libert et al. study included mainly senior oncologists, while our population included junior residents. Second, their study compared physicians whose Rotter I-E scores belonged to the lower third of the distribution (physicians with an "internal" LOC) with physicians whose Rotter I-E scores belonged to the upper third of the distribution (physicians with an "external" LOC), while our study considered the whole distribution of physicians LOC' scores.

Future training programs designed to improve residents' assessment and supportive skills may consider these different predictors and correlates. Concerning assessment skills, trainers need to be aware that the learning of these skills depends on physicians' motivation and that barriers that decrease motivation should be early detected and dealt with appropriately (i.e. low level of self-efficacy, emotional-focused coping). Concerning supportive skills, trainers need to be aware that these skills are difficult to learn and to teach. An appropriate learning of this type of skills may need specific modules. The result that supportive skills are difficult to learn may be explained by the fact that supportive skills include verbal and non-verbal skills (i.e. acknowledgement of a given and fully understood difficulty with an appropriate tone of the voice), while assessment skills include mainly verbal skills (i.e. ask questions).

To conclude, this study shows that predictors of assessment and supportive skills' learning are quite different. While residents' assessment skills' learning is only predicted by residents' psychological characteristics (copings, self-efficacy and depersonalisation), residents' supportive skills' learning is only predicted by their level of work experience and associated with the number of hours of their training attendance. Predictors and correlates are useful to be studied. They may be helpful to increase training efficacy.

\section{Acknowledgements}

The authors wish to thank all the residents who participated in the study.

\section{REFERENCES}

[1] P. Maguire, A. Faulkner, K. Booth, C. Elliott and V. Hillier, "Helping Cancer Patients Disclose Their Concerns," European Journal of Cancer, Vol. 32, No. 1, 1996, pp. 78-81. doi:10.1016/0959-8049(95)00527-7

[2] L. Fallowfield and V. Jenkins, "Effective Communication Skills Are the Key to Good Cancer Care," European Journal of Cancer, Vol. 35, No. 11, 1999, pp. 1592-1597. doi:10.1016/S0959-8049(99)00212-9

[3] D. H. Novack, "Therapeutic Aspects of the Clinical Encounter," Journal of General Internal Medicine, Vol. 2, No. 5, 1987, pp. 346-355. doi:10.1007/BF02596174

[4] G. Wyshak and A. J. Barsky, "Relationship between Patient Self-Ratings and Physician Ratings of General Health, Depression, and Anxiety," Archives of Family Medicine, Vol. 3, No. 5, pp. 419-424.

doi:10.1001/archfami.3.5.419

[5] J. T. Ptacek and T. L. Eberhardt, "Breaking Bad News. A Review of the Literature," JAMA, Vol. 276, No. 6, 1996, pp. 496-502. doi:10.1001/jama.276.6.496

[6] P. Maguire, K. Booth, C. Elliott and B. Jones, "Helping Health Professionals Involved in Cancer Care Acquire Key Interviewing Skills-The Impact of Workshops," European Journal of Cancer, Vol. 32, No. 9, 1996, pp. 1486-1489. doi:10.1016/0959-8049(96)00059-7

[7] N. Delvaux, I. Merckaert, S. Marchal, Y. Libert, S. Conradt, J. Boniver, et al., "Physicians' Communication with a Cancer Patient and a Relative: A Randomized Study Assessing the Efficacy of Consolidation Workshops," Cancer, Vol. 103, No. 11, 2005, pp. 2397-2411. doi:10.1002/cncr.21093

[8] H. Ryan, P. Schofield, J. Cockburn, P. Butow, M. Tattersall, J. Turner, et al., "How to Recognize and Manage Psychological Distress in Cancer Patients," European Journal of Cancer, Vol. 14, No. 1, 2005, pp. 7-15. doi:10.1111/j.1365-2354.2005.00482.x

[9] L. Zandbelt, E. Smets, F. Oort, M. Godfried, H. de Haes, "Determinants of Physicians' Patient-Centred Behaviour in the Medical Specialist Encounter," Patient Education and Counseling, Vol. 63, No. 4, 2006, pp. 899-910. 
[10] S. Newell, R. W. Sanson-Fisher, A. Girgis and A. Bonaventura, "How Well Do Medical Oncologists' Perceptions Reflect Their Patients' Reported Physical and Psychosocial Problems? Data from a Survey of Five Oncologists," Cancer, Vol. 83, No. 8, 1998, pp. 1640-1651. doi:10.1002/(SICI)1097-0142(19981015)83:8<1640::AID -CNCR21>3.3.CO;2-R

[11] J. McCool and J. Morris, "Focus of Doctor-Patient Communication in Follow-Up Consultations for Patients Treated Surgically for Colorectal Cancer," Journal of Management in Medicine, Vol. 13, No. 2-3, 1999, pp. 169-177. doi:10.1108/02689239910292062

[12] I. Merckaert, Y. Libert, N. Delvaux, S. Marchal, J. Boniver, A. M. Etienne, et al., "Factors That Influence Physicians' Detection of Distress in Patients with Cancer: Can a Communication Skills Training Program Improve Physicians' Detection?" Cancer, Vol. 104, No. 2, 2005, pp. 411-421. doi:10.1002/cncr.21172

[13] G. Makoul, "The Interplay between Education and Research about Patient-Provider Communication," Patient Education and Counseling, Vol. 50, No. 1, 2003, pp. 7984. doi:10.1016/S0738-3991(03)00085-5

[14] L. Fallowfield, V. Jenkins, V. Farewell, J. Saul, A. Duffy and R. Eves, "Efficacy of a Cancer Research UK Communication Skills Training Model for Oncologists: A Randomised Controlled Trial," Lancet, Vol. 359, No. 9307, 2002, pp. 650-656. doi:10.1016/S0140-6736(02)07810-8

[15] A. S. Robbins, D. R. Kauss, R. Heinrich, I. Abrass, J. Dreyer and B. Clyman, "Interpersonal Skills Training: Evaluation in an Internal Medicine Residency," Journal of Medical Education, Vol. 54, No. 11, 1979, pp. 885894.

[16] W. A. Langewitz, P. Eich, A. Kiss and B. Wossmer, "Improving Communication Skills-A Randomized Controlled Behaviorally Oriented Intervention Study for Residents in Internal Medicine," Psychosomatic Medicine, Vol. 60, No. 3, 1998, pp. 268-276.

[17] D. J. Cegala and S. Lenzmeier Broz, "Physician Communication Skills Training: A Review of Theoretical Backgrounds, Objectives and Skills," Medical Education, Vol. 36, No. 11, 2002, pp. 1004-1016. doi:10.1046/j.1365-2923.2002.01331.x

[18] R. L. Hulsman, W. J. Ros, J. A. Winnubst and J. M. Bensing, "Teaching Clinically Experienced Physicians Communication Skills. A Review of Evaluation Studies," Medical Education, Vol. 33, No. 9, 1999, pp. 655-668. doi:10.1046/j.1365-2923.1999.00519.x

[19] R. L. Hulsman, "Shifting Goals in Medical Communication. Determinants of Goal Detection and Response Formation," Patient Education and Counseling, Vol. 74, No. 3, 2009, pp. 302-308. doi:10.1016/j.pec.2008.12.001

[20] Y. Libert, I. Merckaert, C. Reynaert, N. Delvaux, S. Marchal, A. M. Etienne, et al., "Physicians Are Different When They Learn Communication Skills: Influence of the Locus of Control," Psychooncology, Vol. 16, No. 6, 2007, pp. 553-562. doi:10.1002/pon.1098

[21] J. A. Colquitt, J. A. LePine and R. A. Noe, "Toward an Integrative Theory of Training Motivation: A Meta-
Analytic Path Analysis of 20 Years of Research," Journal of Applied Psychology, Vol. 85, No. 5, 2000, pp. 678-707. doi:10.1037/0021-9010.85.5.678

[22] I. Bragard, D. Razavi, S. Marchal, I. Merckaert, N. Delvaux, Y. Libert, et al., "Teaching Communication and Stress Management Skills to Junior Physicians Dealing with Cancer Patients: A Belgian Interuniversity Curriculum," Support Care Cancer, Vol. 14, No. 5, 2006, pp. 454-461. doi:10.1007/s00520-005-0008-3

[23] D. L. Roter, "Observations on Methodological and Measurement Challenges in the Assessment of Communication during Medical Exchanges," Patient Education and Counseling, Vol. 50, No. 1, 2003, pp. 17-21. doi:10.1016/S0738-3991(03)00074-0

[24] R. Hogenraad, C. Daubies and Y. Bestgen, "Une Théorie et Une Méthode Générale D’Analyse Textuelle Assistée par Ordinateur," Le système PROTAN, PROTocol ANalyzer, Version 02.03.95, 1995.

[25] P. Stone, D. Dunphy, M. Smith and D. Ogilvie, "The General Inquirer: A Computer Approach to Content Analysis," The MIT Press, Cambridge, 1966.

[26] D. Razavi, I. Merckaert, S. Marchal, Y. Libert, S. Conradt, J. Boniver, et al., "How to Optimize Physicians' Communication Skills in Cancer Care: Results of a Randomized Study Assessing the Usefulness of Posttraining Consolidation Workshops," Journal of Clinical Oncology, Vol. 21, No. 16, 2003, pp. 3141-3149. doi:10.1200/JCO.2003.08.031

[27] K. Booth and P. Maguire, "Development of a Rating System to Assess Interaction between Cancer Patients and Health Professionals," Cancer Research Campaign, London, 1991.

[28] S. Cohen-Cole, "The Medical Interview: The Three-Function Approach," Mosby Year Book, St. Louis, 1991.

[29] A. Gibon, J. Durieux, I. Merckaert, N. Delvaux, C. Farvacques, Y. Libert, et al., "Development of the Lacomm, a French Medical Communication Analysis Software: A Study Assessing Its Sensitivity to Change," Psychooncology, Vol. 19, 2010, pp. 133-134.

[30] A. Lienard, I. Merckaert, Y. Libert, I. Bragard, N. Delvaux, A. M. Etienne, et al., "Is It Possible to Improve Residents' Breaking Bad News Skills? A Randomised Study Assessing the Efficacy of a Communication Skills Training Program," British Journal of Cancer, Vol. 103, 2010, pp. 171-177. doi:10.1038/sj.bjc.6605749

[31] P. Pariente, H. Challita, M. Mesba and J. Guelfi, "The GHQ-28 Questionnaire in French: A Validation Survey," European Psychiatry, Vol. 7, 1992, pp. 15-20.

[32] I. Salehi, "La Théorie de L'Apprentissage Social de la Personnalité de J. B. Rotter: Le Concept de Lieu de Contrôle du Renforcement," Journal of Behavior Therapy, Vol. 2, 1981, pp. 103-117.

[33] L. Lemyre and R. Tessier, "Hypothesis: The Research Page-Measuring Psychological Stress-Concept, Model, and Measurement Instrument in Primary Care Research," Canadian Family Physician, Vol. 49, 2003, pp. 11591160.

[34] M. P. I. Bruchon-Schweitzer, "Manuel Inventaire D'Anxiété 
Etat-Trait Forme Y (STAY-Y),” ECPA, Paris, 1993.

[35] G. Dion and R. Tessier, "Validation de la Traduction de L'Inventaire D'Épuisement Professionnel de Maslach et Jackson," Revue Candienne des Sciences du Comportement, Vol. 26, No. 2, 1994, pp. 210-227. doi:10.1037/0008-400X.26.2.210

[36] I. Paulhan, J. Nuissier, B. Quintard, F. Cousson and M. Bourgeois, "Evaluation of the Coping-Translation and Validation of Vitaliano Scale," Annales Medico-Psychologiques, Vol. 152, No. 5, 1994, pp. 292-299.

[37] M. Parle, P. Maguire and C. Heaven, "The Development of a Training Model to Improve Health Professionals' Skills, Self-Efficacy and Outcome Expectancies When Communicating with Cancer Patients," Social Science \& Medicine, Vol. 44, No. 2, 1997, pp. 231-240. doi:10.1016/S0277-9536(96)00148-7

[38] C. D. Spielberger, "Professional Manual for the Job Stress Survey," Psychological Assessment Resources, Odessa, 1991.

[39] SPSS, "SPSS Base 13.0 for Windows User's Guide Chicago,” SPSS, Inc., Chicago, 2004. 